\title{
MUDANÇAS DE VOLUME DEVIDO À VARIAÇÃO DO TEOR DE ÁGUA EM UM VERTISSOLO NO SEMIÁRIDO DE PERNAMBUCO(1)
}

\author{
Silvio Romero de Melo Ferreira ${ }^{(2)}$ \& Maria da Graça de Vasconcelos \\ Xavier Ferreira ${ }^{(3)}$
}

\begin{abstract}
RESUMO
A instabilidade volumétrica de solos devido à mudança no teor de água é complexa e influenciada por vários fatores, entre os quais se incluem o tipo de solo, condicionantes climáticos e estados de tensão. Os Vertissolos estão entre os solos que experimentam mudança de volume, sendo uma de suas principais características morfológicas os slickensides, resultantes da sua capacidade de se contrair e fissurar com o ressecamento e se expandir com o umedecimento. Os solos que variam de volume, quando inundados por água, demandam cuidado extra, independentemente do uso que se quer dar a eles: agropecuário, para obra de engenharia ou ambos. O objetivo deste trabalho foi avaliar, por meio de ensaios edométricos simples e duplos com diferentes valores de umidade inicial e tensões externas aplicadas, a variação do volume e da tensão de expansão do solo, devido à mudança do teor de água, em um Vertissolo coletado no município de PetrolândiaPE. A tensão de expansão foi avaliada por seis métodos distintos. Os resultados mostram que a expansão, contração ou colapso do solo dependem do teor de umidade inicial e da tensão externa aplicada. A tensão de expansão é influenciada pelo caminho de tensão aplicado. As variações de volume, com o tempo, devido ao processo de mudança de umidade do solo, podem ser de expansão, expansão e colapso e só de colapso ou contração. Conclui-se que a variação de volume, devido à variação do teor de água, está associada à condição inicial em que se encontra o solo e àquela a que será submetido.
\end{abstract}

Termos de indexação: solo expansivo, tensão de expansão, solos não saturados.

\footnotetext{
(1) Recebido para publicação em junho de 2008 e aprovado em maio de 2009.

(2) Professor Titular da Universidade Católica de Pernambuco e Adjunto da Universidade Federal de Pernambuco - UFPE. Av Prof. Luiz Freire 1000, CEP 50740-540 Recife (PE). E-mail: sr.mf@hotmail.com.br

(3) Professora Adjunta da Universidade Católica de Pernambuco - UNICAPE. Rua do Príncipe 526, Boa Vista, CEP 50050-900 Recife (PE). E-mail: mariadagracaferreira@yahoo.com.br
} 


\title{
SUMMARY: VOLUME CHANGES DUE TO MOISTURE VARIATION IN A VERTISOIL IN THE SEMI-ARID REGION OF PERNAMBUCO STATE, BRAZIL
}

\begin{abstract}
The volumetric instability of soils due to changes in the water content is complex and is influenced by several factors, such as soil type, climate conditions and tension state. Vertissols are soils that undergo variations in volume. One of their most important morphological features are slickensides that reflect contraction and fissuring during the drying process, and swelling during wetting. Soils that vary in volume when flooded require special care regardless of their use for agriculture, construction or both. The objective of this study was to evaluate, through both conventional edometric tests and suction-controlled tests, with different initial moisture and externally applied tension, the changes in volume and expansion tension of the soil, due to variations in the water content of a Vertisol from Petrolândia-PE. The expansion tension was measured by six methods. Results showed that soil expansion, contraction or collapse depend on the initial moisture and external tension. The expansion tension is influenced by the tension path. The volume variations with time when the soil is drying could be due to expansion, expansion and collapse and only collapse or contraction. It was concluded that the volume changes due to the water content variation are associated to the soil initial conditions and those that the soil is expected to undergo in the future.
\end{abstract}

Index terms: expansive soil, expansion tension, unsaturated soils.

\section{INTRODUÇÃO}

O fenômeno de instabilidade volumétrica (contração e expansão ou colapso) de solos devido à mudança no teor de água é complexo e influenciado por vários fatores, entre os quais se incluem o tipo de solo, condicionantes climáticos e estados de tensão (Delgado, 1986; Justo et al., 1984).

Para que um solo possa exibir expansividade, é necessário o preenchimento de dois requisitos: devem existir, e entrar em funcionamento, mecanismos que, na dimensão microescalar, produzam a instabilidade volumétrica do solo; e devem estar presentes forças capazes de transferir a água de um ponto a outro do solo, o que implica um desequilíbrio da umidade natural do entorno. Esses requisitos podem ser classificados em intrínsecos e extrínsecos (Chen, 1988). Os primeiros são próprios do solo (composição mineralógica, textura e estrutura) e estabelecem a capacidade expansiva teórica; os outros são impostos por fatores externos, como clima, disponibilidade hídrica, biota e atuação antrópica, e determinam se o potencial expansivo se concretiza ou não.

O caráter expansivo de um solo depende, primeiramente, de um fator intrínseco, do tipo de mineral existente na fração argila, uma vez que nem todos os filossilicatos relacionados a essa fração experimentam modificações volumétricas quando inundados por água. Essa instabilidade é importante nos minerais $2: 1$, como nas vermiculitas e nas esmectitas, especialmente na montmorilonita (Mitchell, 1976). Também está presente nos minerais interestratificados, regulares ou não, desde que faça parte uma espécie expansiva, como, por exemplo, montmorilonita com clorita e mica com vermiculita.
Existem também outros fatores condicionantes ligados ao solo (distribuição das partículas de argila, porosidade, orientação mineralógica, cimentação, perfil estratigráfico, espessura do solo, descontinuidade litológica, etc.) que influenciam secundariamente o seu potencial expansivo.

Entre os fatores extrínsecos, a disponibilidade de água é o preponderante. Mudanças sazonais de umidade, ao longo do ano, estão vinculadas ao clima, enquanto as oscilações periódicas de umidade, na superfície do terreno, dependem da relação precipitação/evapotranspiração. A evapotranspiração, por sua vez, está condicionada ao tipo e à exuberância da vegetação, além dos fatores ligados à atmosfera, que são umidade, velocidade do vento e temperatura do ar.

Se, em um determinado período, a precipitação exceder a evapotranspiração e a umidade do solo superar a capacidade de campo, produz-se, por drenagem, a eliminação do excesso de água infiltrada. Essa água, dependendo da estratigrafia da área, pode dar lugar a um nível freático ou alimentar um já existente. Nessas condições, as alterações sazonais de umidade são pouco frequentes.

Ocorre o inverso quando as precipitações estão concentradas em determinadas estações; nos meses de seca a evapotranspiração excede a precipitação. Esse déficit tende a se compensar a partir da água retida no terreno. A umidade perdida será, então, recuperada nos períodos de chuva. O resultado final são mudanças sazonais de umidade na camada mais superficial do solo.

Os Vertissolos estão entre os solos que experimentam mudança de volume, sendo uma de suas principais características morfológicas os 
slickensides, resultantes da sua capacidade de se contrair e fissurar com o ressecamento e se expandir com o umedecimento.

A respeito do fissuramento, Ahmad (1983) afirmou que geralmente há correlação inversa entre intensidade e largura das fissuras. Há indicações de que o grande número de fissuras finas é característico das argilas com predominância de carbonatos de sódio livres, ao passo que o número menor de fissuras maiores é das argilas com predominância de carbonatos de cálcio livres (Ahmad, 1983).

Já a mudança de volume, devido à variação de aplicação da tensão externa ou da sucção, é governada, primordialmente, pela presença da água nas bordas das partículas dos argilominerais (Mitchell, 1976).

Os solos que variam de volume, quando inundados por água, quer colapsíveis, quer expansivos, demandam cuidado extra, independentemente do uso que se quer dar a eles: agropecuário, para obra de engenharia ou ambos. Frise-se que não há como evitar esses comportamentos, uma vez que são inerentes.

Nos expansivos, o processo é reversível e qualquer uso que dele se faça causará interferência, influenciando, por exemplo, a intensidade do fissuramento. Na agropecuária, a aragem e a falta de cobertura vegetal ou morta expõem mais o solo ao ressecamento. Há também que se levar em consideração o adensamento causado pelas máquinas e pelo pisoteio dos animais, se for pasto, além da vedação superficial, em razão do impacto da chuva.

No entanto, quando esse uso é para a construção civil ou requer obras de engenharia, como canais de irrigação e agrovilas, é preciso uma atenção especial, visto que a implantação de uma obra provoca, inevitavelmente, modificação da umidade natural do solo. A fase de escavação expõe à evaporação mais intensa as cotas superficiais dos terrenos. Já depois da execução da obra, impede-se tanto o acesso vertical de água ao terreno como as perdas por evaporação, criando um desequilíbrio em relação aos terrenos circundantes, o que pode induzir movimentos de umidade. As transferências são favorecidas em climas quentes, pelo maior aquecimento do solo experimentado no entorno das construções, por não estar ele protegido da insolação. O resultado final pode ser uma camada úmida, sob a zona construída, que leva ao intumescimento do solo ou, alternativamente, ao desenvolvimento de tensões. Essas instabilidades podem ser muito pronunciadas se durante a realização das obras foi permitida uma forte dessecação do terreno.

Portanto, o cuidado com esses solos inicia-se já na fase de projeto, passando por todas as etapas da construção, até o pós-uso, uma vez que o comportamento do solo pode acarretar danos à obra (fissuras, trincas ou rupturas), diminuindo a sua vida útil ou até, em situações extremas, inviabilizando-a (Presa, 1982; Ahmad, 1983).
O estudo do comportamento ativo do solo, das propriedades dos argilominerais, dos cátions do complexo sortivo e dos condicionantes climáticos é de grande importância para o entendimento dos mecanismos envolvidos na variação de volume.

Há vários métodos para avaliar a tensão de expansão do solo, envolvendo diferentes trajetórias de tensão. Os métodos mais citados na literatura (Figura 1) compreendem: (1) carregamento após expansão com diferentes sobrecargas; (2) expansão e colapso sob tensão; (3) volume constante; (4) ensaio edométrico duplo; (5) Rao et al. (1988); e (6) Justo et al. (1984). A diferença fundamental entre os métodos é a ordem seguida entre a aplicação de tensão e a inundação. No método 1, a amostra é inundada primeiro e carregada depois; no método 2 , a amostra é carregada primeiro e inundada depois; no método 3 , inundação e carregamento ocorrem simultaneamente; no método 4, são dois corpos de prova, um carregado na umidade natural e outro inundado e carregado posteriormente; no método 5 , inicialmente ocorre como no método 3 até a tensão de expansão a volume constante e, posteriormente, eleva-se o carregamento, comprimindo o solo; e no método 6, proposto por Justo et al. (1984), a curva de inundação sob tensão depende mais do estado de tensão do solo.

Delgado (1986) realizou ensaios para obter a tensão de expansão de uma argila compactada de alta plasticidade coletada da Barreira La Paz de Arahal-A (Serillia), e Silva \& Ferreira (2007) também o fizeram em uma argila de Pesqueira-PE. Os valores das tensões de expansão obtidas pelos autores supracitados, utilizando seis métodos, são apresentados no quadro 1 .

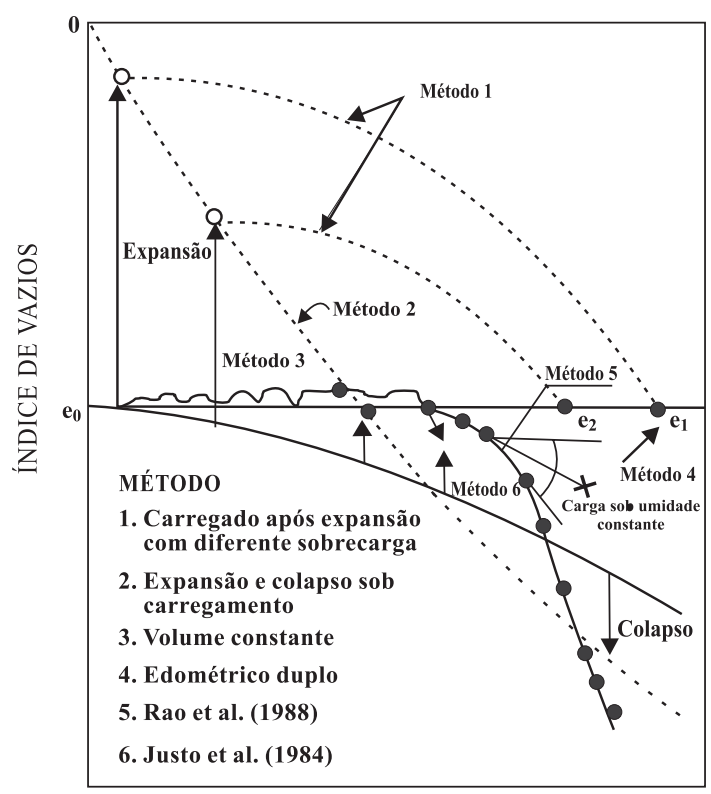

TENSÃO VERTICAL DE CONSOLIDAÇÃO

Figura 1. Métodos para determinação da tensão de expansão. 
Esses autores concluem que os valores da tensão de expansão, determinados utilizando os diferentes métodos, são influenciados pela trajetória de tensão seguida nos ensaios.

Delgado (1986) analisou a influência da tensão aplicada na expansão "livre", realizando uma série de ensaios com pequenas tensões aplicadas $(0,15,1,80$, $7,40$ e $12,00 \mathrm{kPa})$, em uma argila compactada ArahalA com grau de compactação de $100 \%$ e umidade de $22 \%$, de alta plasticidade, coletada da Barreira La Paz de Arahal (Serilla). Verificou que, quanto menor a tensão vertical aplicada, maiores os valores da expansão "livre" e a dispersão dos resultados.

Ferreira (1995) analisou as características químicas, mineralógicas e microestruturais de um Vertissolo com horizonte A fraco, fase caatinga hiperxerófila, relevo plano de Petrolândia-PE, e concluiu que a sua matriz é caracterizada por textura fina, compacta, predominantemente de argilas silicatadas permeadas por cristais de calcita micrítica, que compõem grande parte da fração silte e areia fina. Encontrou grande quantidade de pápulas, por vezes lameladas e provavelmente provenientes de enchimento de canais e poros aplanados, destruídos e empurrados na matriz do solo, devido à ação da argila de atividade alta (Ta) que ocorre nesse solo. Os nódulos calcíticos encontrados, segundo Ferreira (1995), são típicos e comuns, como também a reprecipitação de carbonato de cálcio $\left(\mathrm{CaCO}_{3}\right)$ nas paredes dos poros. É um solo pouco desenvolvido, profundo ou de moderada profundidade e de textura argilosa. Compõem a fração argila, entre os filossilicatos, a caulinita, a mica e o interestratificado irregular de esmecita, vermiculita e mica. É pouco poroso, moderado ou imperfeitamente drenado, de permeabilidade moderada no horizonte A e lenta no $\mathrm{C}$, sendo suscetível à erosão. Possui elevada saturação por base (valor $\mathrm{V}=100 \%$ ), com reação moderadamente alcalina ( $\mathrm{pH}$ de $8,0-8,5)$.
O presente estudo teve por objetivo avaliar a variação de volume e a tensão de expansão do Vertissolo do município de Petrolândia-PE estudado por Ferreira (1995), com diferentes valores de umidade inicial e tensão vertical externa aplicada, resultantes do aumento ou da redução da quantidade de água no solo, em laboratório.

\section{MATERIAL E MÉTODOS}

Neste trabalho são analisadas as características de variação de volume, devido à mudança do teor de água, de um Vertissolo do município do Estado de Pernambuco, Petrolândia, distante 520 km, a oeste, da cidade do Recife. O local selecionado para estudo está inserido na Bacia Sedimentar do Jatobá. A litologia da área de ocorrência do Vertissolo é representada por sedimentos da Formação Aliança, constituídos por siltitos, folhelhos e calcários de cores castanho e avermelhada. Os solos desenvolvidos nessa formação são bastante característicos, mostrando-se argilosos ou siltosos, e com cores escuras, normalmente de cinza-escuro a avermelhado (Melo, 1980). Observam-se, em campo, fendas de dessecação.

$\mathrm{O}$ estudo desenvolveu-se em duas etapas. $\mathrm{Na}$ primeira, em campo, foram realizados poços de investigação com coleta de amostras (indeformadas do tipo bloco e deformadas em sacos) na superfície e em profundidade, segundo a ABNT (1986b), e determinações dos índices físicos umidade (gravimétrica) e peso específico do solo, por um período de dois anos, em estações chuvosas e secas. Na segunda, em laboratório, foram feitos preparação de amostras (ABNT, 1986a) e ensaios de caracterização para determinação do limite de liquidez (ABNT, 1984b), do limite de plasticidade (ABNT, 1984d), da massa específica (ABNT, 1984c) e análise granulométrica (ABNT, 1984a). Para obtenção da

Quadro 1. Tensões de expansão obtidas por seis métodos de determinação em uma argila expansiva compactada de Arahal - Serilla, Delgado (1986), e em uma argila expansiva de alta plasticidade de Pesqueira-PE, Silva \& Ferreira (2007)

Método de tensão de expansão
Tensão de expansão

Delgado (1986) Silva \& Ferreira (2007)

1- Carregamento após expansão com diferentes sobrecargas

2- Expansão e colapso sob tensão

3- Volume constante

4- Ensaio edométrico duplo

5- Rao et al. (1988)

6- Justo et al. (1984)

Média

\begin{tabular}{cc}
\hline 260 & $\mathrm{kPa}$ \\
150 & 168 \\
193 & 365 \\
290 & 110 \\
- & 180 \\
200 & 140 \\
219 & 310
\end{tabular}


relação umidade (gravimétrica) e sucção utilizaramse amostras coletadas entre as profundidades de $0,6 \mathrm{e}$ 1,0 m, membrana de tensão com valores aplicados de 1 a $10.000 \mathrm{kPa}$ e dessecadores a vácuo com diferentes concentrações de cloreto de sódio (Baker, 1973), que permitiram aplicar sucções de 200 a $8.000 \mathrm{kPa}$, e de ácido sulfúrico (Aitchison \& Richards, 1965), que permitiram aplicar sucções de 5.000 a $100.000 \mathrm{kPa}$.

Para avaliar o efeito do pré-umedecimento ou dessecamento, amostras indeformadas coletadas entre as profundidades de 0,6 m e 1,0 m foram moldadas em anéis com áreas de $8.000 \mathrm{~mm}^{2}$ e altura de $30,0 \mathrm{~mm}$ e colocadas em dessecadores, com diferentes concentrações de cloreto de sódio ou ácido sulfúrico, por dez meses até o peso ficar constante e, posteriormente, moldadas em anéis de áreas de $4.000 \mathrm{~mm}^{2} \mathrm{e}$ altura de $20,0 \mathrm{~mm}$, para realização de ensaios edométricos simples. Para análise do efeito do dessecamento sob tensão, amostras indeformadas, com umidade gravimétrica de $17,41 \%$, foram moldadas, carregadas a tensões específicas e, posteriormente, permitiu-se a perda de umidade, sob tensão, em temperatura ambiente, até estabilização das deformações, o que ocorreu entre 60 e 70 dias.

Os ensaios edométricos simples ou duplos foram realizados em amostras indeformadas coletadas entre as profundidades de 0,6 e 1,0 m, moldadas em anéis de aço inoxidável de paredes finas com altura de $20,0 \mathrm{~mm}$ e diâmetro de $71,3 \mathrm{~mm}$. Os corpos de prova foram carregados a uma tensão vertical predeterminada e posteriormente inundados, sendo medidas as deformações de compressão, de colapso ou de expansão. O papel-filtro, colocado em contato prévio com uma amostra do solo, alcançava a umidade de equilíbrio, evitando, portanto, perda ou ganho de umidade antes da inundação. O topo da célula, por sua vez, foi envolvido por um plástico e fixado com borracha, impedindo a perda de umidade durante o processo de carregamento, antes da inundação. No início do ensaio, uma tensão de 1,0 kPa era aplicada, a fim de se fazer o assentamento do sistema e a leitura inicial para o processo de deformação. As tensões aplicadas nos ensaios tiveram acréscimo $(\Delta \sigma)$ igual ao da tensão anterior $(\Delta \sigma / \sigma=1)$, sendo o valor inicial de $10 \mathrm{kPa}$ e o final de $1.280 \mathrm{kPa}$. O tempo de duração de cada estádio de tensão, antes da inundação, era tal que a deformação entre dois intervalos de tempo $(\Delta \mathrm{t})$ consecutivos $(\Delta t / t=1)$ era inferior a $5 \%$ da deformação total do solo ocorrida até o tempo anterior, e na tensão de inundação era de, no mínimo, $24 \mathrm{~h}$. Alem das tensões de inundação supracitadas, para melhor avaliar a tensão de expansão e a variação de volume, duas outras tensões de inundação foram utilizadas: 240 e $400 \mathrm{kPa}$. No descarregamento, as tensões foram de 640, 160, 40 e $10 \mathrm{kPa}$. A figura 2 ilustra as quatro etapas do ensaio.

Os ensaios para determinar a expansão "livre" foram realizados em células edométricas convencionais com anéis de aço inoxidável de altura de $20,0 \mathrm{~mm}$ e

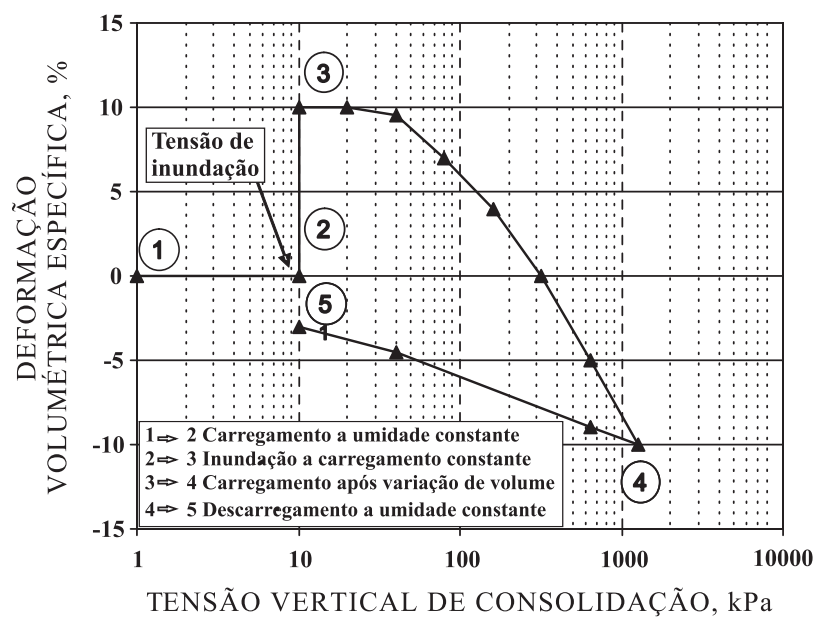

Figura 2. Etapas dos ensaios edométricos simples.

diâmetro de 71,3 mm e em célula de expansão com $20,0 \mathrm{~mm}$ de altura e diâmetro de $40,7 \mathrm{~mm}$. Os corpos de prova foram submetidos a pequenas tensões, que variaram de 1 a $10 \mathrm{kPa}$. A expansão do solo após inundação com água foi acompanhada até a estabilização.

Os valores dos potenciais de colapso (CP) ou de expansão (SP), obtidos por meio dos ensaios edométricos simples, foram calculados pelas equações:

$$
C P(\%)=\frac{\Delta H}{H_{i}} \times 100 \% \text { ou } S P(\%)=\frac{\Delta H}{H_{i}} \times 100 \%
$$

em que $\Delta$ H é a variação da altura do corpo de prova devido à inundação e $\mathrm{H}_{\mathrm{i}}$ é a altura do corpo de prova antes da inundação.

A tensão de expansão foi determinada por seis métodos diferentes em amostras indeformadas coletadas entre as profundidades de 0,6 e 1,0 m, com umidade de 17,41\%. O método 1 - "Carregamento após expansão com diferentes sobrecargas" consiste em aplicar uma tensão $\sigma_{0}$ numa amostra confinada lateralmente, que é levada a expandir por inundação. A deformação específica é medida em intervalos de tempo, até a estabilização ser alcançada. Após a estabilização, a amostra é consolidada com aumento da tensão aplicada, até que a altura inicial seja alcançada. A tensão máxima obtida é a tensão de expansão da amostra. Esse procedimento é repetido para um mínimo de três corpos de prova, e a tensão de expansão do solo é a média. O método 2 - "Expansão e colapso sob tensão" consiste em aplicar uma tensão $\mathrm{s}_{0}$ numa amostra do solo, que, após consolidação, é inundada, sendo medida a deformação ocorrida. Marca-se em papel semilogaritmo o ponto correspondente à tensão aplicada e deformação ocorrida. Repete-se o procedimento para mais dois corpos de prova, no mínimo. Com esses pontos traça-se uma reta, e a tensão de expansão é obtida por extrapolação, correspondente à deformação zero. O método 3 "Volume constante" consiste em medir diretamente 
no edômetro a tensão necessária para impedir a mudança de volume do solo depois de inundá-lo. No método 4 - "Edométrico duplo" a tensão de expansão é a tensão que corresponde, no corpo de prova inundado, ao mesmo índice de vazios inicial do corpo de prova na umidade natural. No método 5 - "Rao et al. (1988)", após a determinação da tensão de expansão pelo método de volume constante, aplicam-se sucessivamente pequenos incrementos de tensão no corpo de prova, quando inundado, procurando impedir a mudança de volume. Em seguida, continua-se a aplicar tensões, como no ensaio de adensamento convencional. A tensão de expansão é obtida por procedimento gráfico similar à determinação da tensão de pré-consolidação de um solo saturado. O método 6 - "Justo et al. (1984)" consiste em determinar a tensão de expansão a partir da interseção das curvas de inundação sob tensão e de deformação em umidade constante.

\section{RESULTADOS E DISCUSSÃO}

\section{Caracterização física}

Observou-se, em campo, no período seco, que as fissuras, na superfície do solo, tinham espessuras que variavam de poucos milímetros a $120,0 \mathrm{~mm}$, reduzindo de dimensão com a profundidade, e a extensão chegou a atingir 2,0 m (observada no poço). Para a penetração da água, as fissuras mais largas são mais importantes do que uma grande intensidade de fissuras finas, porque, além de a água fluir de forma mais rápida, atinge maior profundidade, a umidade aumenta e o solo expande. As fissuras menores são progressivamente restringidas pela expansão do solo, enquanto as maiores podem permanecer abertas por um período mais longo de tempo. No início do processo de umedecimento, a intensidade do fissuramento é tão importante quanto a largura e profundidade das fissuras individuais. Com as chuvas, o solo absorveu água a partir da superfície, expandiu-se, tornou-se mais plástico e gerou-se o microrrelevo.

$\mathrm{Na}$ superfície formaram-se blocos irregulares, sendo detectados, em uma área de 100,0 m², escolhida de forma aleatória em campo, cerca de 190, tendo cada um uma área média de 0,53 $\mathrm{m}^{2}$ (Figura 3a). Há slickensides e fendilhamento no período seco, sendo a consistência muito plástica e muito pegajosa no período chuvoso. Esses fendilhamentos interferem no tamanho e forma da estrutura e no relevo superficial, desenvolvendo microrrelevo.

No Vertissolo de Petrolândia-PE, predominavam carbonatos de cálcio livres sobre os de sódio (Ferreira, 1995), apresentando assim um número menor de fissuras de maior largura, confirmando as indicações de Ahmad (1983). Observa-se, também, que após o período de chuvas houve desaparecimento completo de algumas fissuras na superfície.

O teor de água do solo, medido da superfície a uma profundidade de $3,50 \mathrm{~m}$, varia, no período chuvoso, de 42 a $20,90 \%$, e no período seco, de 14,54 a 21,03\% (Figura $3 b$ ). A partir de 2,50 $\mathrm{m}$ de profundidade, praticamente não houve, nos dois anos de observação, variação do teor de água entre o período seco e o chuvoso, indicando ser essa a zona ativa de mudança do teor de água.

A tensão de expansão do solo, obtida pelo método de volume constante, cresce com a profundidade no período chuvoso, e no seco decresce até $2,5 \mathrm{~m}$; a partir desta profundidade, fica praticamente constante (Figura 4a). De igual modo, observa-se, com a profundidade, a relação entre a tensão de expansão e a tensão efetiva (Figura 4b). Até a profundidade de 2,5 m há influência significativa dos condicionantes climatológicos na umidade, na tensão de expansão e na profundidade em que ocorre fissura. Em campo, as fissuras foram observadas até $2,0 \mathrm{~m}$ de profundidade, no período seco. (a)

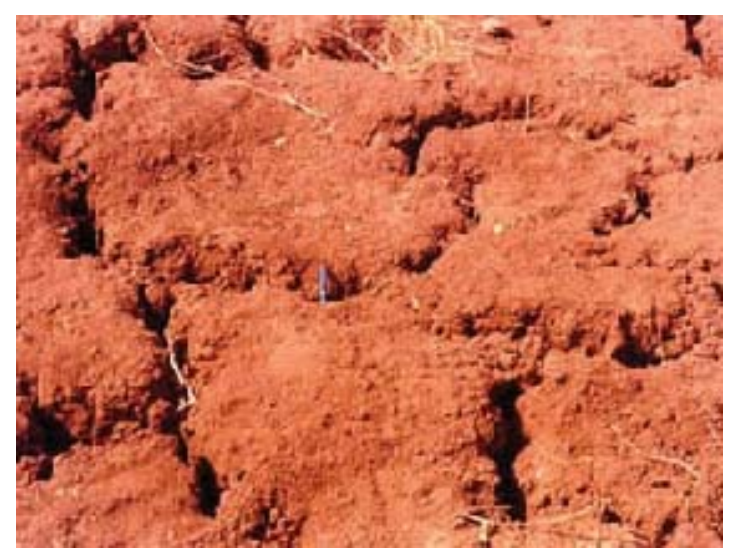

(b)

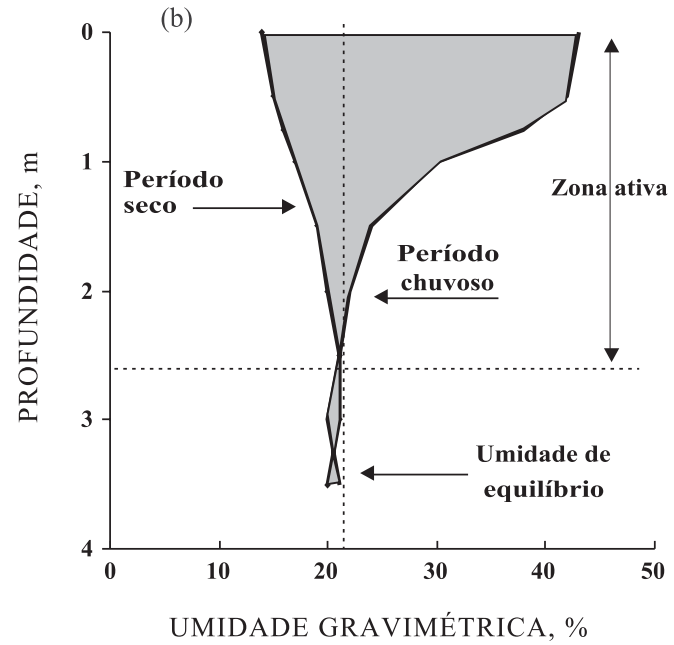

Figura 3. Vertissolo de Petrolândia-PE: (a) fissuras e microrrelevos em período seco; (b) variação da umidade com a profundidade, do período seco ao chuvoso. 


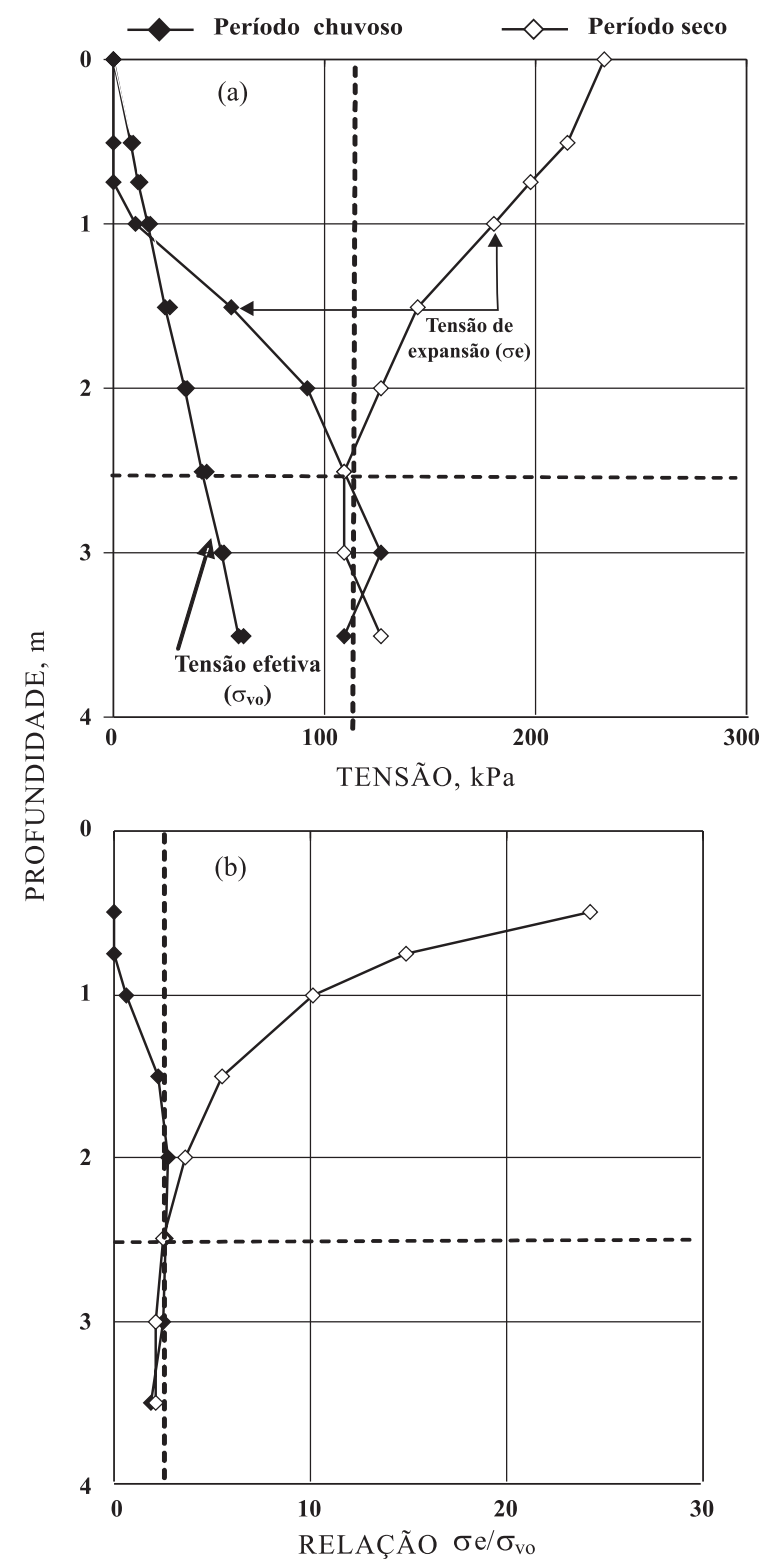

Figura 4. Variação, em diferentes profundidades, das tensões efetivas e de expansão obtida pelo método de volume constante em amostras coletadas nos períodos chuvoso e seco: (a) variação da tensão de expansão e efetiva em diferentes profundidades; (b) relação entre a tensão de expansão e a tensão efetiva.

Em relação à granulometria (Figura 5), o Vertissolo de Petrolândia-PE apresenta variação discreta de percentuais de constituintes ao longo do perfil. A percentagem de argila $(<0,002 \mathrm{~mm})$ é superior a $54 \%$ e inferior a $60 \%$, e a de areia (diâmetros dos grãos entre 0,02 e $2 \mathrm{~mm}$ ) varia de 3 a $8 \%$. A relação silte/argila decresce com a profundidade, indicando ter havido translocação do material mais fino da superficie para horizontes subsuperficiais, carreado pela água e percolado pelas fissuras. A sucção (Ua-Uw), no período seco, é elevada, variando de 1.000 a
$15.000 \mathrm{kPa}$ (Figura 5). O limite de liquidez é $60 \%$, o índice de plasticidade, de $30 \%$, e o limite de contração, de $19 \%$, tendo, portanto, alta plasticidade e consistência dura, encontrando-se, em campo (no período seco), com umidade natural inferior ao limite de contração, até a profundidade de 1,0 m.

\section{Comportamento de mudança de volume}

O comportamento de variação de volume devido à inundação é analisado considerando a influência da tensão vertical de inundação, da tensão de expansão, da umidade inicial e da secagem sob tensão.

\section{Influência da tensão vertical de consolidação}

As curvas de deformação versus tempo, após inundação, correspondentes ao trecho $2 \rightarrow 3$ na figura 2 do ensaio edométrico simples, são mostradas na figura 6. O processo de deformação de expansão e, ou, colapso é, às vezes, simultâneo; portanto, o que se mede é a resultante, que é função da tensão vertical, de índice de vazios e da umidade (estado de tensão) em que se encontra o solo antes de ser inundado com água. Assim, para um determinado estado de tensão, a deformação devido à inundação, medida com o tempo, é só de expansão para tensões inferiores a $160 \mathrm{kPa}$; expansão e colapso para tensões de 240 e $400 \mathrm{kPa}$ (o solo inicialmente comprime até $8 \mathrm{~min}$, em seguida expande até $240 \mathrm{~min}$, para depois comprimir até a estabilização das deformações); e só de colapso para tensões superiores a $640 \mathrm{kPa}$.

O processo de deformação de expansão ou colapso, com o tempo, devido à inundação sob tensão de consolidação externa constante, pode ser dividido em três etapas de deformação: (a) inicial - para tempos inferiores a $1 \mathrm{~min}$, em que são observadas pequenas deformações no solo; a água umedece apenas a periferia; (b) primária - para tempos compreendidos entre $1 \mathrm{e}$ $300 \mathrm{~min}$; a água percola da periferia para o centro, umedecendo o solo progressivamente (em função da condutividade hidráulica), e as deformações ocorrem com maior intensidade; e (c) secundária - para tempos superiores a $300 \mathrm{~min}$; a água umedece o núcleo central, os vazios encontram-se quase completamente preenchidos por água e a velocidade de deformação diminui (Figura 6). Roo (2006) considera que as deformações iniciais estão associadas à microestrutura, e as deformações primárias e secundárias, à macroestrutura.

Em função da tensão vertical aplicada ao solo antes da inundação e da variação da estrutura durante o processo de umedecimento, há três situações a considerar (Figura 6): (a) quando a tensão vertical de consolidação é baixa (inferior a $160 \mathrm{kPa}$ ), em relação à tensão de expansão do solo, a inundação causa uma expansão que se processa com facilidade. A tensão externa não causa maior efeito na consolidação do solo, com a estrutura modificada, resultando em uma expansão tanto maior quanto menor for a tensão de consolidação; e (b) quando a tensão vertical de 


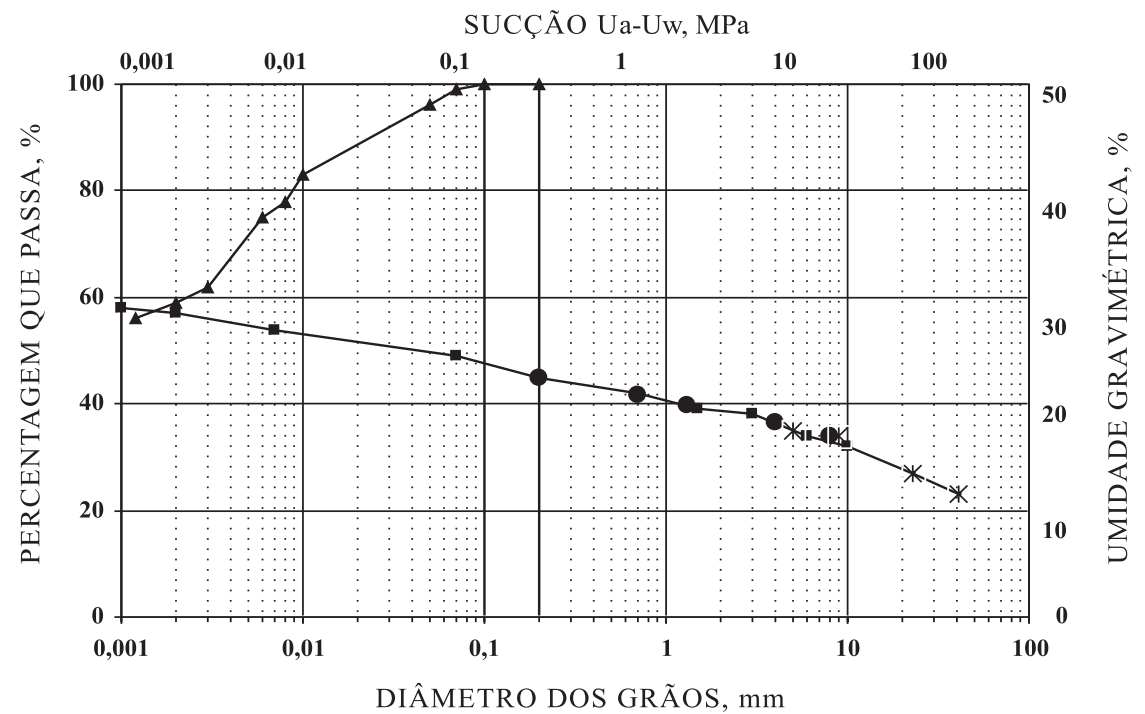

Figura 5. Curvas granulométrica e de retenção de água.

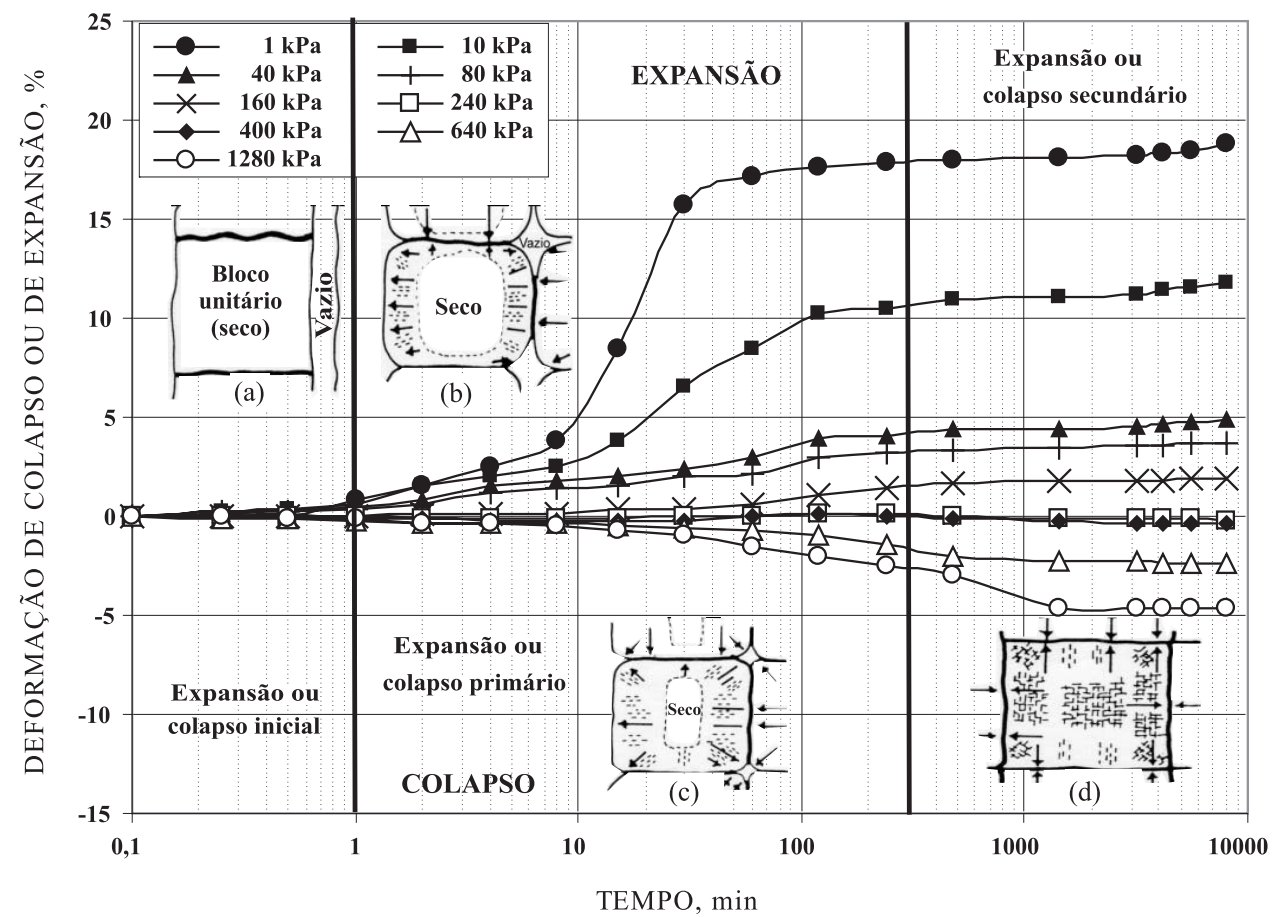

Figura 6. Comportamento de variação de deformação com o tempo sob tensão com avanço da frente de umedecimento: (a) há pequena alteração na umidade do solo; (b) há mudança de umidade na periferia do solo; (c) apenas o núcleo central mantém a umidade inicial; (d) há mudança de umidade em todo o solo.

consolidação é elevada (maior do que $640 \mathrm{kPa}$ ), superior à tensão de expansão do solo, com a inundação, as partículas tendem a se orientar, formando uma estrutura mais dispersa do que quando estava sob baixa tensão vertical. A compressibilidade do solo cresce progressivamente da periferia para o centro da amostra, e, como a tensão vertical de consolidação é maior do que a de expansão, o solo comprime-colapsa; quando a tensão vertical de consolidação é próxima à tensão de expansão (compreendida entre 240 e $400 \mathrm{kPa}$ ), a inundação causa, inicialmente, uma mudança da umidade apenas nas proximidades da superfície do solo, alterando a compressibilidade nessa região. A expansão da dupla camada ocorre de forma parcial, como nos casos anteriores, prevalecendo, inicialmente, o efeito da tensão vertical de consolidação, provocando a compressão do solo sobre a expansão, e o solo comprime-colapsa. Quando a frente de umedecimento avança, a expansão do solo pode prevalecer sobre o 
efeito da tensão vertical de consolidação. A deformação medida, durante o processo, é a resultante dos efeitos da tensão vertical de consolidação, causando compressão sob a expansão da dupla camada, ou vice-versa.

A variação do potencial de expansão ou de colapso, com a tensão vertical de consolidação, com o índice de vazios e com o grau de saturação com água antes da inundação do solo, é mostrada na figura 7. Para tensões inferiores a $312 \mathrm{kPa}$ (Figura 7a), índices de vazios superiores a 0,745 (Figura 7b) e graus de

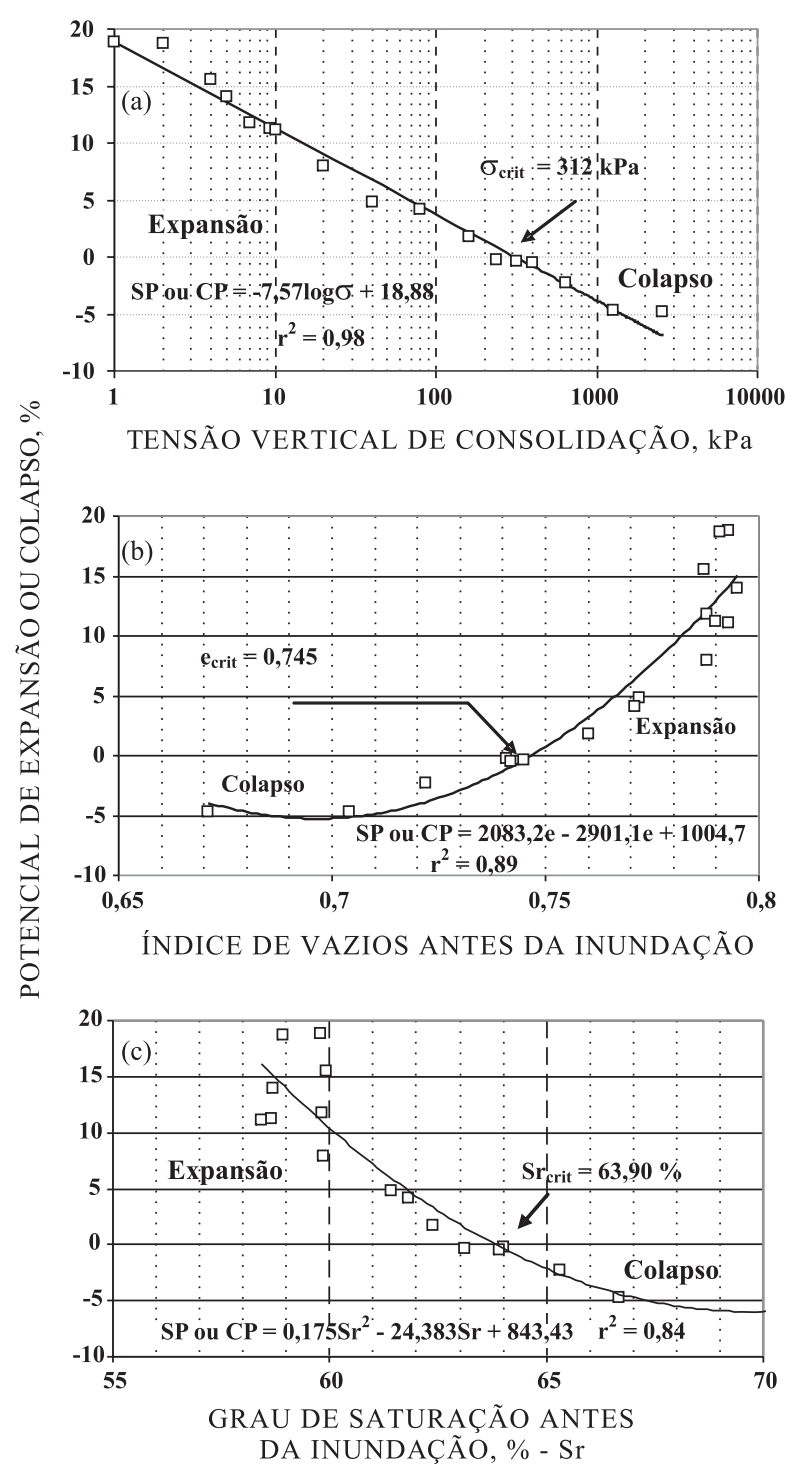

Figura 7. Variação do potencial de expansão ou de colapso obtida nos ensaios edométricos simples: (a) com a tensão vertical de consolidação; (b) com o índice de vazios antes da inundação; (c) com grau de saturação antes da inundação. SP: potencial de expansão; CP: potencial de colapso; e: índice de vazios; Sr: grau de saturação em água; $\sigma:$ tensão; $\mathbf{r}^{2}$ : coeficiente de correlação; crit: crítico. saturação inferiores a 63,90 \% (Figura 7c), o Vertissolo de Petrolândia-PE expande quando há aumento da umidade do solo, caracterizando a região de expansão. Para tensões superiores a $312 \mathrm{kPa}$ (Figura 7a), índices de vazios inferiores a 0,745 (Figura $7 b$ ) e graus de saturação superiores a 63,90 \% (Figura 7c), o Vertissolo de Petrolândia-PE colapsa quando há aumento da umidade do solo, caracterizando a região de colapso. Há uma tensão $\left(\sigma_{\text {crit }}=312 \mathrm{kPa}\right)$, um índice de vazios $\left(\mathrm{e}_{\text {crit }}=0,745\right)$ e um grau de saturação em água $\left(\mathrm{Sr}_{\text {crit }}=63,90 \%\right)$ crítico em que o solo não expande nem colapsa, quando inundado (Figura 7).

\section{Tensão de expansão}

As diferentes trajetórias de tensão aplicadas ao solo, utilizadas para avaliar a tensão de expansão do Vertissolo de Petrolândia-PE, por meio de seis métodos de determinação, são apresentadas na figura 8. A expansão do solo devido à inundação com o tempo, até a estabilização das deformações, para diferentes tensões verticais de inundação (1, 10, 40, 80 e $160 \mathrm{kPa})$ é mostrada na figura 8a, enquanto a figura 8b mostra a consolidação com o acréscimo de tensão até o solo atingir a altura inicial, antes da inundação. O valor médio da tensão de expansão obtido pelo método 1 (Carregamento após expansão com diferentes sobrecargas) é de 333 kPa (Figura 8b).

A relação entre a expansão do solo após estabilização e a tensão vertical de consolidação é aproximadamente linear, e o valor da tensão de expansão determinada pelo método 2 é de $239 \mathrm{kPa}$ (Figura 8c). O valor da tensão de expansão a volume constante (Método 3), impedindo a variação de volume do solo, é de $242 \mathrm{kPa}$; a curva de deformação volumétrica específica é apresentada na figura $8 d$. Após a determinação da tensão de expansão a volume constante, procedeu-se ao carregamento para determinação da tensão de expansão pelo método 5 , de Rao et al. (1988), que considera a tensão de préadensamento determinada pelo método de Casagrande (1932) como a tensão de expansão (Figura 5d). O valor obtido foi de $330 \mathrm{kPa}$. A figura 8e mostra o resultado do ensaio edométrico duplo com a tensão de expansão de $308 \mathrm{kPa}$ (Método 4). A tensão de expansão determinada pelo método 6, de Justo et al. (1984), tem valor de $277 \mathrm{kPa}$ e depende da curva de inundação sob tensão e da curva de carregamento em umidade constante (Figura 8f). A tensão de expansão do solo, obtida pelo método 1 , depende da trajetória de tensão anterior à inundação, notadamente para valores mais baixos da tensão vertical de consolidação. Todas as amostras apresentaram curvas de tensão, posteriores à inundação, superiores à curva de inundação sob tensão (para a faixa de tensão considerada). Esse comportamento explica-se pelo fato de que, uma vez desenvolvido o mecanismo de expansão, a água adsorvida fica fortemente fixada às partículas (Mitchell, 1976), requerendo maior incremento de tensão para diminuição de volume. Se a tensão de inundação for muito baixa, o desenvolvimento do 

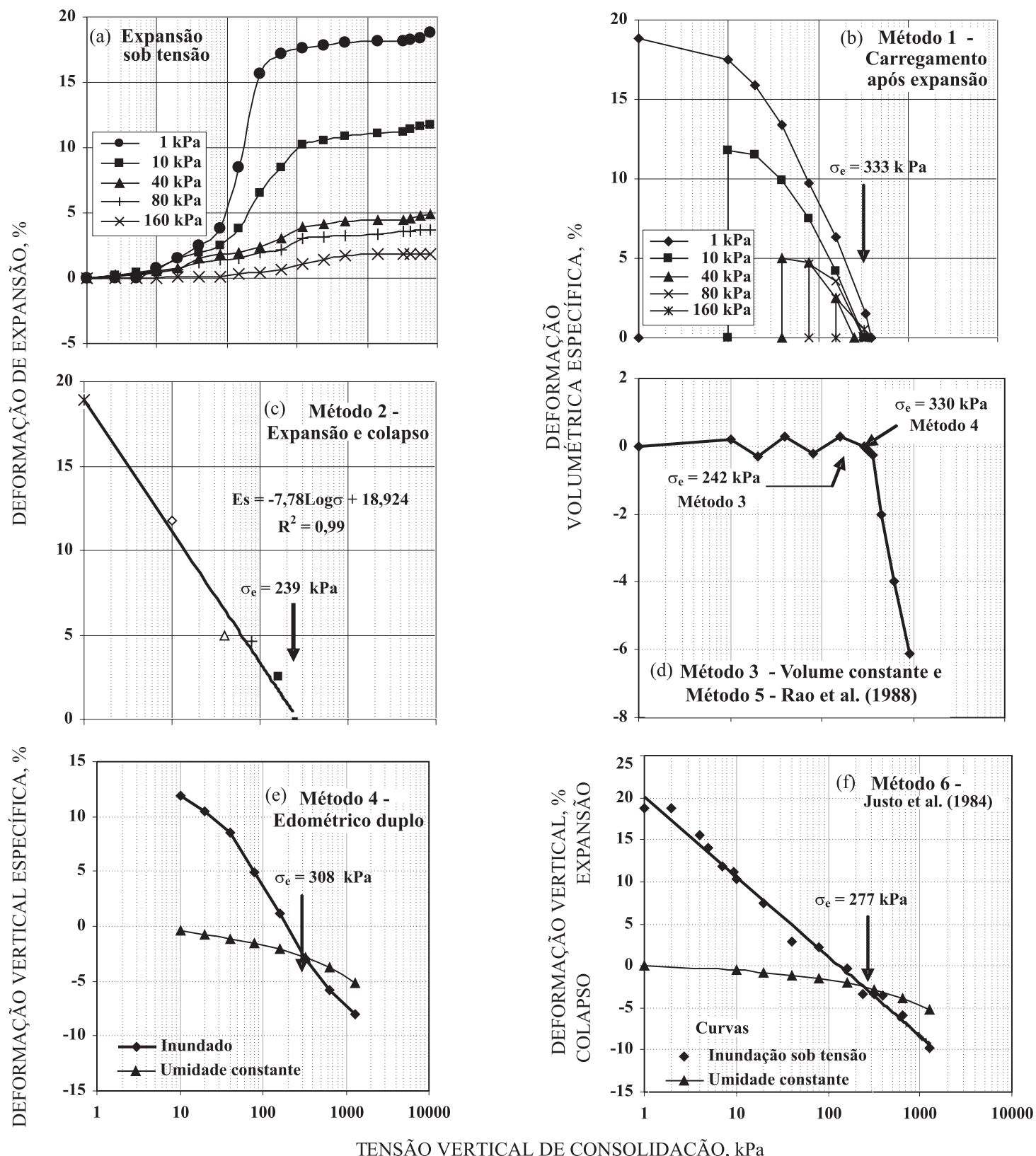

Figura 8. Métodos de tensão de expansão: (a) expansão sob tensão; (b) carregamento após expansão; (c) expansão e colapso; (d) volume constante e Rao et al. (1988); (e) edométrico duplo; (f) Justo et al. (1984). H: horizonte; T: tangente à curva; B: bissetriz do ângulo formado entre a horizontal e a tangente; $\sigma_{\mathrm{e}}$ : tensão de expansão; $\mathbf{r}^{2}$ : coeficiente de correlação.

mecanismo de expansão é mais completo. A trajetória de tensão seguida para a determinação da tensão de expansão, método 1 , tem menor interesse, uma vez que só se aplica, na prática, quando se usa a técnica de inundação prévia à construção. Por outro lado, se a inundação se processa depois (Métodos 2 e 6) ou de forma simultânea (Método 3), o mecanismo de expansão desenvolve-se no solo de forma parcial, por estar sob tensão, alcançando menor umedecimento.

Diferentes valores de tensões de expansão também foram obtidos na argila expansiva de Pesqueira-PE por Silva \& Ferreira (2007), e por Delgado (1986) na argila compactada Arahal-A coletada da Barreira La Paz de Arahal (Serilla), como mostrado no quadro 1.

\section{Influência da umidade inicial}

A variação da expansão "livre" cresce (aproximadamente linear) com o decréscimo do teor de água inicial (acréscimo da sucção) e com o decréscimo da tensão vertical de consolidação antes da inundação (Figura 9a). A expansão "livre" do Vertissolo em estudo na umidade de 17,41 \% é de alta expansividade 


\section{Quadro 2. Influência da umidade inicial na deformação e tensão de expansão}

\begin{tabular}{|c|c|c|c|c|c|c|c|c|}
\hline \multirow{2}{*}{ W } & \multirow{2}{*}{$\begin{array}{l}\text { Sucção } \\
\text { inicial }\end{array}$} & \multirow{2}{*}{$\mathbf{e}_{\mathbf{o}}$} & \multirow{2}{*}{$\rho_{\mathrm{d}}$} & \multirow{2}{*}{$\mathrm{Sr}$} & \multicolumn{2}{|r|}{$\begin{array}{l}\text { Relação deformação } \\
\text { de expansão - tensão }\end{array}$} & \multicolumn{2}{|c|}{ Tensão de expansão } \\
\hline & & & & & & $\begin{array}{ll}\boldsymbol{S} & \sigma\end{array}$ & Método 1 & Método 2 \\
\hline$\%$ & $\mathrm{kPa}$ & & $\mathrm{KN} \mathrm{m}^{-3}$ & $\%$ & & $\mathrm{kPa}$ & $\longrightarrow$ & - \\
\hline 7,76 & 117.000 & 0,597 & 16,96 & 35,22 & $\varepsilon \mathrm{s}=$ & $-11,82 \log \sigma+29,73 r^{2}=0,99$ & 456 & 328 \\
\hline 17,41 & 15.000 & 0,801 & 15,05 & 59,24 & $\varepsilon \mathrm{s}=$ & $-7,84 \log \sigma+18,66 \mathrm{r}^{2}=0,99$ & 333 & 239 \\
\hline 20,70 & 700 & 0,885 & 14,37 & 63,39 & $\varepsilon \mathrm{s}=$ & $-8,62 \log \sigma+16,64 r^{2}=0,99$ & 153 & 83 \\
\hline 22,60 & 200 & 0,936 & 14,00 & 65,43 & $\varepsilon s=$ & $-6,36 \log \sigma+11,60 \mathrm{r}^{2}=0,99$ & 85 & 67 \\
\hline
\end{tabular}

W: umidade inicial no período seco; $e_{0}$ : índice de vazios inicial; Sr: grau de saturação em água; $\varepsilon s$ : deformação de expansão ( $\varepsilon s=$ $100 \Delta \mathrm{H} / \mathrm{H}_{\mathrm{i}}$ em que: $\Delta \mathrm{H}$ é a variação de altura do corpo de prova devido à inundação e $\mathrm{H}_{\mathrm{i}}$ a altura do corpo de prova antes da inundação); $\sigma$ : tensão; $\rho_{\mathrm{d}}$ : peso específico aparente seco; $\mathrm{r}^{2}$ : coeficiente de correlação; método 1: carregamento após expansão com diferentes tensões verticais de consolidação; método 2: expansão e colapso sob tensão.

pelo critério de Vijayvergiya \& Ghazzaly (1973), que consideram tensão de consolidação de $10 \mathrm{kPa}$.

Os valores dos índices físicos dos corpos de prova, que foram previamente umedecidos ou dessecados antes de serem inundados, e os valores das tensões de expansão, determinadas pelos métodos de carregamento após expansão, com diferentes tensões verticais de consolidação e expansão (Método 1) e colapso sob tensão (Método 2), para as umidades iniciais de $22,58,20,80,17,41$ e $7,76 \%$, são apresentados no quadro 2 . Considerando as condições iniciais dos corpos de prova, os maiores valores da tensão de expansão obteve-se para menores valores de umidade $(7,76 \%)$, grau de saturação $(35,22 \%)$ e índice de vazios $(0,57)$ e maiores valores de sucção $(117.000 \mathrm{kPa})$ e peso específico aparente seco $\left(16,96 \mathrm{KN} / \mathrm{m}^{3}\right)$. O umedecimento prévio do solo causa redução na tensão de expansão, e o dessecamento, acréscimo; isso mostra que no campo os condicionantes climatológicos têm influência significativa na tensão de expansão do solo. A declividade da relação deformação de expansão x tensão tende ao crescimento (em valor absoluto) com o decréscimo da umidade inicial (acréscimo da sucção inicial).

As curvas de deformação volumétrica específica com a tensão vertical de consolidação $\left(\varepsilon_{\mathrm{v}} \mathrm{X} \sigma-\log \right)$ do solo com diferentes umidades iniciais, e inundadas nas tensões de 10 e $160 \mathrm{kPa}$, são apresentadas na figura 9b. Para uma mesma umidade inicial, a expansão devida à inundação reduz com o aumento da tensão vertical de consolidação, e para uma mesma tensão vertical de consolidação, a expansão do solo reduz com o acréscimo da umidade inicial (Figura 9b), porque o processo de umedecimento prévio causa expansão antes do carregamento. Sob a tensão vertical de consolidação de $160 \mathrm{kPa}$, a inundação do solo causa colapso para as umidades iniciais de 22,58 e $20,80 \%$ e expansão para as umidades iniciais de 17,41 e 7,76 \% (Figura 9c). Comportamento similar foi encontrado por Presa (1982) para um solo com aproximadamente o mesmo índice de vazios e diferentes umidades iniciais, consolidado sob tensão de $200 \mathrm{kPa}$. A umidade inicial e a tensão a que o solo está submetido têm importância significativa no comportamento de variação de volume quando o solo é inundado.

\section{Secagem sob tensão}

O processo de deformação do solo por dessecação, sob tensão, com o tempo, é muito mais lento do que durante o umedecimento. Isso se deve à forma de transferência de umidade, que, durante a inundação, se processa na fase líquida, enquanto na dessecação se processa, em parte, na fase de vapor.

O efeito da dessecação na deformação total do solo é maior para tensões mais baixas do que para tensões maiores (Figura 10a). As deformações medidas durante a dessecação resultam da soma de três componentes: compressão imediata, deformação devida à magnitude da tensão vertical com o tempo e retração propriamente dita, com o tempo. Para tensões menores que $40 \mathrm{kPa}$, o tempo para ocorrer $50 \%$ das deformações é de, no mínimo, oito dias, enquanto para tensões maiores que $320 \mathrm{kPa}$ é de, no máximo, dois dias. Isso é explicado pelo fato de que, para tensões de consolidação menores que $40 \mathrm{kPa}$, as compressões imediatas e às devidas ao efeito da tensão são reduzidas com o tempo quando comparadas com as provocadas pela dessecação, preponderando, fundamentalmente, aquelas resultantes da retração, que são mais lentas. Quanto às tensões maiores que $320 \mathrm{kPa}$, as compressões imediatas e às devidas aos efeitos da magnitude da tensão têm maior importância e ocorrem mais rapidamente do que as causadas pela dessecação. A região entre as curvas de carregamento em umidade constante e de dessecação sob tensão delimita a região de contração (Figura 10b).

As curvas de inundação sob tensão e carregamento em umidade constante delimitam duas regiões: a primeira, de expansão para tensões inferiores a 

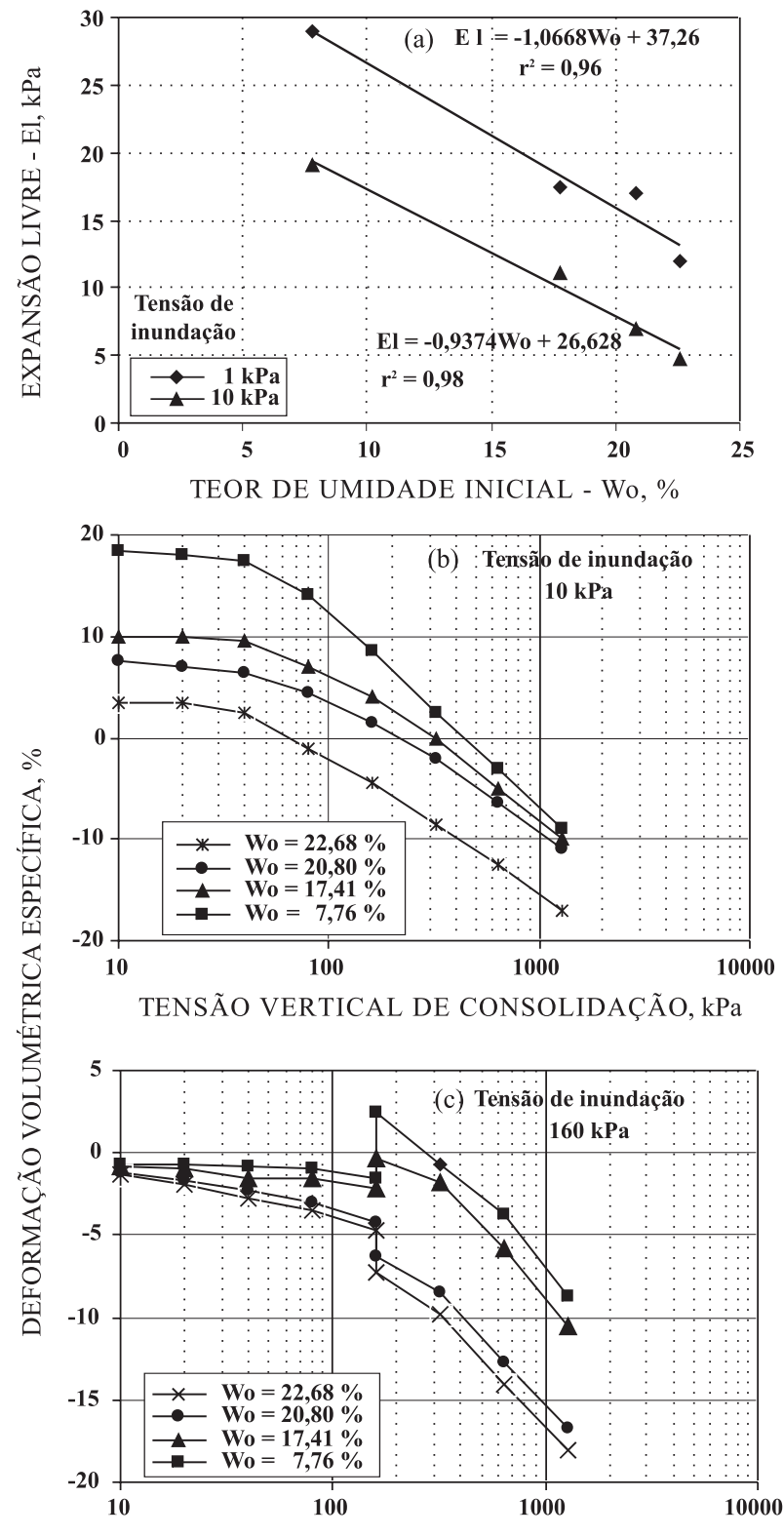

TENSÃO VERTICAL DE CONSOLIDAÇÃO, kPa

Figura 9. Influência da umidade inicial: (a) na expansão "livre"; (b) na compressibilidade; e (c) na expansão ou colapso sob tensão. EI: expansão livre; Wo: umidade gravimétrica inicial; $\mathbf{r}^{2}$ : coeficiente de correlação.

$277 \mathrm{kPa}$ (no Vertissolo de Petrolândia-PE há expansão quando a umidade cresce - Figura 10b); e a segunda, de colapso para tensões superiores a $277 \mathrm{kPa}$. O conjunto formado pelas curvas de inundação sob tensão, carregamento a umidade constante e dessecação sob tensão constitui uma importante informação sobre a influência da trajetória de tensão no comportamento de variação de volume devido à mudança da umidade no solo. Eles delimitam regiões de expansão, colapso e contração.
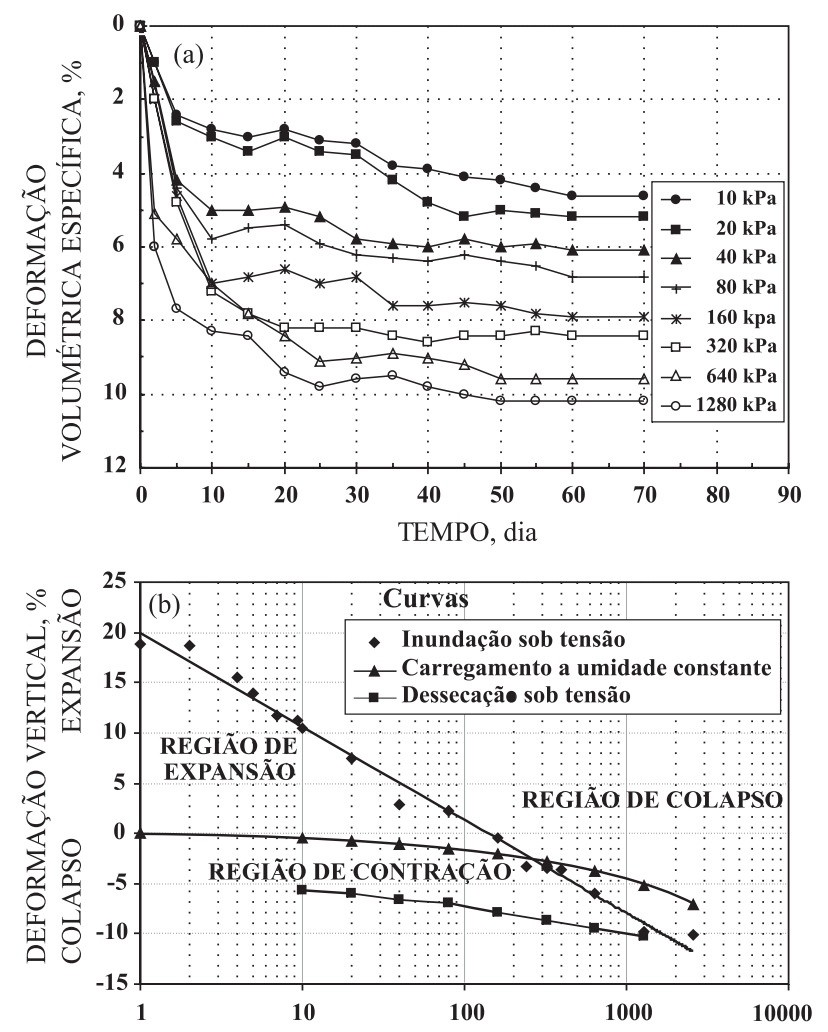

TENSÃO VERTICAL DE INUNDAÇÃO, $\mathrm{kPa}$

Figura 10. Deformação volumétrica com acréscimo de tensão, dessecação e inundação: (a) deformação volumétrica com acréscimo de tensão e dessecação simultânea; (b) regiões de expansão, colapso e contração.

\section{CONCLUSÕES}

1. A expansão devido ao acréscimo de umidade é maior para o solo com menor umidade inicial e maior tensão vertical externa aplicada.

2. A ordem com que o solo é solicitado ou inundado influencia o valor da tensão de expansão.

3. A tensão de expansão a ser considerada no projeto deve ser aquela que melhor representa a condição de campo.

4. Em função da umidade inicial e da tensão vertical aplicada ao solo, a inundação leva a aumento de volume (expansão) ou diminuição (colapso).

5. O conjunto formado pelas curvas de inundação sob tensão, carregamento em umidade constante e dessecação sob tensão delimita regiões de expansão, colapso e contração.

\section{LITERATURA CITADA}

AHMAD, N. Vertisols. In: WILDINY L.P.; SMECK, N.E. \& HALL, G.F. Pedogenesis and soil taxonomy. Amsterdam, Elsevier, 1983. p.91-123. 
AITCHISON, G.D. \& RICHARDS, B.G. A broad-scale study of moisture conditions in pavement subgrades throughout Australia. In: Moisture covered areas. Sidney, Butterworths, 1965. p.226-232.

ASSOCIAÇÃO BRASILEIRA DE NORMAS TÉCNICAS ABNT. NBR 6457. Preparação para ensaios de compactação e ensaios de caracterização. Rio de Janeiro, 1986a.

ASSOCIAÇ̃̃O BRASILEIRA DE NORMAS TÉCNICAS ABNT. NBR 7181. Solos: Análise granulométrica conjunta. Rio de Janeiro, 1984a.

ASSOCIAÇÃO BRASILEIRA DE NORMAS TÉCNICAS ABNT. NBR 6459. Solo: Determinação do limite de liquidez. Rio de Janeiro, 1984b.

ASSOCIAÇÃO BRASILEIRA DE NORMAS TÉCNICAS ABNT. NBR 6508. Grãos de solos que passam na peneira de $4,8 \mathrm{~mm}$ - Determinação da massa específica. Rio de Janeiro, 1984c.

ASSOCIAÇÃO BRASILEIRA DE NORMAS TÉCNICAS ABNT. NBR 7180. Solo: Determinação do limite de plasticidade. Rio de Janeiro, 1984d.

ASSOCIAÇÃO BRASILEIRA DE NORMAS TÉCNICAS ABNT. NBR 9604. Abertura de poço e trincheira de inspeção em solo, com retirada de amostras deformadas e indeformadas. Rio de Janeiro, 1986b.

BAKER, R.; KASSIF, G. \& LOVY, A. Experience with a psychometric technique. In: INTERNATIONAL CONFERENCE ON EXPANSIVE SOILS, 3., Haifa, 1973. Proceedings. Haifa, 1973. p.83-96.

CASAGRANDE, A. The structure of clay and its importance in foundation engineering. J. Boston Soc. Civil Eng., 19:168-209, 1932.

CHEN, F.H. Foundations on expansive soils. 2.ed. Amsterdam, Elsevier Science Publications, 1988. 463p.
DELGADO, A. Influencia de la trayectoria de las tensiones en el comportamiento de las arcillas expansivas y de los suelos colapsables en el laboratorio y en el terreno. Sevillia, Universidad de Sevillia, 1986. 564p. (Tese de Doutorado)

FERREIRA, S.R.M. Colapso e expansão de solos naturais não saturados devidos à inundação. Rio de Janeiro, Universidade Federal do Rio de Janeiro, 1995. 379p. (Tese de Doutorado)

JUSTO, J.L.A.; DELGADO, A. \& RUIZ, J. The influence of stress-path in the collapse-swelling of soils at the laboratory. In: INTERNATIONAL CONFERENCE ON EXPANSIVE SOILS, 5., Adelaide, 1984. Proceedings, 1984. p.67-71.

MELO, J.G. Estudo hidrológico da bacia sedimentar do Jatobá (PE) recursos exploráveis e dispositivos de captação. Recife, Universidade Federal de Pernambuco, 1980. 332p. (Tese de Mestrado)

MITCHELL, J.K. Fundamentals of soil behavior. New York, John Wiley \& Sons, 1976. 422p.

PRESA, E.P. Deformabilidad de las argillas expansivas bajop succión controlada. Madrid, Universidad Politécnica de Madrid, 1982. 663p. (Tese de Doutorado)

RAO, R.R.; RAHARDJO, H. \& FREDJUND, D.G. Close from heave solutions for expansive soils. J. Geotechnol. Eng. A.S.C.E., 114, 5:573-588, 1988 .

ROO, S.M. Identification and classification of expansive soils In: AL-RAMS, A.A. \& GOOSEN, M.F.A., eds. London, Taylor \& Francis/Balkema, 2006. p.15-24.

SILVA, M.J.R. \& FERREIRA, S.R.M. Estudo da variação de volume de um solo expansivo de Pesqueira/PE. In: SIMPÓSIO BRASILEIRO DE SOLOS NÃO SATURADOS, 6., Salvador, 2007. Anais. Salvador, Associação Brasileira de Mecânica dos Solos e Engenharia Geotécnica, 2007. p.159-164.

VIJAYVERGIYA, V.N. \& GHAZZALY, O.I. Prediction of swelling potential for natural clays. In: INTERNATIONAL CONFERENCE ON EXPANSIVE SOILS, 3., Hayfa, 1973. Proceedings. Hayfa, 1973. p.227-236. 
